emerging paradigm within primary care to focus not only on disease (pathogenesis) but also on health (salutogenesis) might open new avenues for sexual health counselling. New technology also has potential: continuous education sessions have limited impact on prescribing habits for infrequent conditions with fast changing resistance patterns like gonoccocal infections; learning GP to use more and better their electronic prescription expert-system based on patient ICPC code (Prescriptor) is a better option and now available in most GP operating systems in the Netherlands.

\section{P5-S6.28 HIV PREVENTION BASED ON THE STATIC MODES OF TRANSMISSION SYNTHESIS FOR TWO INDIAN DISTRICTS: INSIGHTS FROM DYNAMICAL MODELLING}

doi:10.1136/sextrans-2011-050108.584

${ }^{1} \mathrm{~S}$ Mishra, ${ }^{2} \mathrm{P}$ Vickerman, ${ }^{1} \mathrm{M}$ Pickles, ${ }^{3} \mathrm{~B} \mathrm{M}$ Ramesh, ${ }^{3} \mathrm{R}$ Washington, ${ }^{3} \mathrm{~S}$ Issac, ${ }^{4} \mathrm{~S}$ Moses, ${ }^{4} \mathrm{~J}$ Blanchard, ${ }^{1} \mathrm{M}$ C Boily. ${ }^{1}$ Imperial College, London, UK; ${ }^{2}$ London School of Hygiene and Tropical Medicine, UK; ${ }^{3}$ Karnataka Health Promotion Trust, Bangalore, India; ${ }^{4}$ Centre for Global Public Health, Canada

Background The Modes of Transmission (MOT) synthesis uses a static HIV transmission model to predict distribution of incident infections along subgroups over 1 year, and directs HIV prevention along this distribution. Because the MOT does not consider where sustained transmission is most likely to occur, and does not use parameter combinations fitted to observed epidemic characteristics, its relevance for planning interventions may be limited.

Methods We fitted a dynamical HIV/STI heterosexual transmission model to districts Mysore and Belgaum, India. The MOT and dynamical models estimated the proportion of new HIV infections over 1 year due to transmission between female sex workers/clients, their non-commercial partnerships, and low-risk partnerships. We compared predictions from the dynamical model to MOT results using prior and posterior (fitted) parameters. Intervention impact was illustrated using the dynamical model.

Results Using prior inputs, the MOT predicted that commercial sex accounted for $66.2-70.6 \%$ of incident infections among males, whereas $71.7-74.2 \%$ of incident infections among females were due to bridging infections from clients. There was less variability in MOT results when fitted inputs were used. The majority of the remaining new infections in males and females were due to transmission within low-risk partnerships. In contrast, the dynamical model predicted a higher contribution of commercial sex among males (90.7-91.2\%), a higher contribution of bridging infections among females $(70.5-86.9 \%)$, and that $<1.5 \%$ of infections were due to low-risk partnerships. Dynamical modelling predicted that any intervention that reduces transmission by $20 \%$ applied among commercial sex partnerships could decrease overall HIV incidence by $12 \%$ in the first year and by $21 \%$ in 5 years see Abstract P5-S6.28 table 1. Applying this intervention among non-commercial partnerships of clients reduces overall incidence by $9 \%$ in years 1 through 5 because clients continue to become infected from their commercial partnerships.

Conclusion Prior inputs for the MOT will not reflect observed HIV prevalence, and as a result, will produce greater variability in MOT predictions. Allocating resources along a 1-year distribution of incident infections can prioritise prevention to the wrong subgroups because they do not account for the dynamic effects of interventions. Improved methods of epidemic appraisals are urgently needed to guide prevention programming.

\section{P5-S6.29 INTENSIVE USE OF A CLINICAL DOCUMENTATION AUDIT TOOL TO BRING ABOUT SUSTAINED IMPROVEMENT IN THE STANDARD OF RECORD-KEEPING IN A BUSY GENITO- URINARY MEDICINE (GUM) CLINIC}

doi:10.1136/sextrans-2011-050108.585

W Spice, R Whitby, S Bhaduri. Worcestershire Primary Care Trust, Worcester, UK

Introduction Accuracy and consistency in clinical note-keeping is an essential element of clinical governance. In this busy GUM clinic, up to 12 different healthcare practitioners (both nurses and doctors) see patients for their history and examination, as well as taking tests, making microscopic diagnoses, giving treatment and notifying contacts. With this many staff of differing clinical backgrounds seeing patients autonomously, it is important that minimum standards of documentation are maintained. This study reports the use of an audit tool designed to provide clinic workers with regular feedback on their individual record-keeping performance compared to the clinic as a whole, thereby identifying areas where documentation standards can be improved.

Methods The audit was started in January 2009 and carried out monthly for 12 months with three sets of clinical notes audited per clinician each month. Collective scores for the clinic were issued on a monthly basis, with individual clinicians also receiving their own scores confidentially every quarter. The audit was discontinued for a year, then repeated so as to evaluate the extent to which improvements made in the first year had been maintained. Clinicians were unaware that the re-audit was taking place. The audit was based on 31 separate criteria divided into administrative ( 7 criteria), clinical (20 criteria) and health adviser (4 criteria) sections. This report focuses on the outcome of the clinical section, which included criteria such as adequacy of history and examination records, choice of tests conducted, consistency of diagnoses with findings, and suitablility of treatments prescribed. The internal standard was set at $100 \%$ for each criterion.

Results Overall scores for individual clinicians in the first month ranged from $72 \%$ to $96 \%$, with median $82 \%$ and mean $83 \%$. At month 12 , the range was $87-100 \%$, median $98 \%$, mean $97 \%$. The

Abstract P5-S6.28 Table 1 Distribution of 1-year incident infections by type of partnership, as predicted by the MOT and a fitted dynamical model

\begin{tabular}{|c|c|c|c|c|c|c|c|}
\hline & \multirow[b]{3}{*}{ Partnership type } & \multicolumn{6}{|c|}{ Median $\%$ of incident infections attributable to partnership types (2.5 and 97.5 percentiles) } \\
\hline & & \multicolumn{2}{|l|}{ MOT (prior inputs) } & \multicolumn{2}{|c|}{ MOT (posterior inputs) } & \multicolumn{2}{|l|}{ Dynamical model } \\
\hline & & Mysore & Belgaum & Mysore & Belgaum & Mysore & Belgaum \\
\hline \multirow[t]{4}{*}{ Females } & Commercial & $6.5(2.4,14.9)$ & $5.1(1.9,12.2)$ & $7.0(3.3,13.0)$ & $4.5(2.0,8.8)$ & $28.4(18.6,35.5)$ & $11.7(5.7,15.0)$ \\
\hline & Main partnerships of FSWs/Clients & $71.7(50.4,88.7)$ & $74.2(48.6,90.9)$ & $75.6(61.0,87.8)$ & $73.0(55.4,84.9)$ & $70.5(63.6,80.3)$ & $86.9(83.5,92.9)$ \\
\hline & Casual partnerships of FSWs/Clients & $0.03(0.01,0.09)$ & $0.01(0.003,0.04)$ & $0.02(0.01,0.07)$ & $0.01(0.004,0.04)$ & $0.30(0.25,0.38)$ & $0.31(0.23,0.38)$ \\
\hline & Low-risk & $20.0(4.6,40.7)$ & $19.4(4.3,44.3)$ & $15.8(7.1,29.3)$ & $21.8(10.9,38.7)$ & $0.76(0.31,1.1)$ & $1.0(0.61,1.4)$ \\
\hline \multirow[t]{4}{*}{ Males } & Commercial & $70.6(21.4,92.6)$ & $66.2(14.3,92.8)$ & $66.0(40.6,81.1)$ & $69.1(41.7,84.3)$ & $91.2(90.8,95.6)$ & $90.7(88.4,96.1)$ \\
\hline & Main partnerships of FSWs/Clients & $9.8(3.4,21.3)$ & $10.8(3.6,20.9)$ & $11.3(6.1,20.2)$ & $9.6(4.2,19.5)$ & $6.3(3.4,8.1)$ & $7.3(2.9,9.2)$ \\
\hline & Casual partnerships of FSWs/Clients & $2.0(0.5,4.0)$ & $4.5(1.2,9.9)$ & $1.7(0.66,3.7)$ & $3.8(1.3,8.3)$ & $0.5(0.3,0.6)$ & $0.87(0.51,1.2)$ \\
\hline & Low-risk & $15.6(2.8,58.5)$ & $13.0(1.6,65.8)$ & $19.7(10.0,36.9)$ & $14.9(6.0,35.4)$ & $0.6(0.3,0.9)$ & $1.0(0.37,1.4)$ \\
\hline
\end{tabular}

FSW, female sex worker; MOT, Modes of Transmission. 
repeat audit conducted after a 12 -month lapse revealed overall scores ranging from 89 to $100 \%$, median $98 \%$, mean $97 \%$.

Conclusions This study shows that it is possible to substantially improve standards of clinical record-keeping in a GUM clinic staffed by clinicians from a variety of backgrounds, through the intensive application of a wide-ranging audit tool and the use of individual feedback. The repeat audit conducted a year after the 12-month intensive phase shows that these improvements appear to be both sustainable and durable.

\section{P5-S6.30 HPV CATCH-UP VACCINATION AMONG A COMMUNITY SAMPLE OF YOUNG ADULT WOMEN}

doi:10.1136/sextrans-2011-050108.586

L Manhart, A Burgess-Hull, C Fleming, J Bailey, K Haggerty, R Catalano. University of Washington (Seattle, USA)

Background Despite the high efficacy of the human papillomavirus (HPV) vaccine, uptake has been slow and little data on psychosocial barriers to catch-up vaccination exist.

Methods A community sample of 428 women enrolled in a longitudinal study of social development were interviewed about HPV vaccine status, attitudes, and barriers to HPV vaccination in spring 2008 or 2009 at $\sim$ age 22 .

Results $19 \%$ of women had initiated vaccination, $10 \%$ had completed the series, and $\sim 40 \%$ of unvaccinated women intended to get vaccinated. Peer approval was associated with vaccine initiation (Adjusted Prevalence Ratio (APR) 2.5; 95\% CI 1.7 to 3.8) and intention to vaccinate (APR 1.5; 1.2-1.9). Belief the vaccine is $<75 \%$ effective was associated with less initiation (APR 0.6; $0.4-0.9$ ) or intention to vaccinate (APR 0.5; 0.4-0.7). Vaccine initiation was also less likely among cigarette smokers and illegal drug users, whereas intention to vaccinate was more common among women currently attending school or with $>5$ lifetime sex partners, but less common among women perceiving low susceptibility to HPV (APR 0.6; 0.4-0.8) see Abstract P5-S6.30 table 4.

Conclusions HPV catch-up vaccination uptake was low in this community sample. Increasing awareness of susceptibility to HPV and the high vaccine efficacy, along with peer interventions to increase acceptability, may be most effective.

Abstract P5-S6.30 Table 4 Multivariable analyses of characteristics independently associated with vaccine initiation and intention to vaccinate among 428 young women who participated in the Raising Healthy Children (RHC) young adult survey during 2008 and 2009

\begin{tabular}{|c|c|c|c|c|}
\hline & \multicolumn{2}{|l|}{ Vaccine initiation } & \multicolumn{2}{|c|}{ Intention to vaccinate } \\
\hline & APR $(95 \% \mathrm{CI})^{*}$ & $\bar{p}$ Value & APR $(95 \% \mathrm{CI})^{*}$ & p Value \\
\hline Daily smoker & $0.5(0.30$ to 0.90$)$ & 0.02 & - & - \\
\hline Illegal drug use $†$ & $0.3(0.07$ to 0.99$)$ & 0.05 & - & - \\
\hline $\begin{array}{l}\text { Pelvic exam in the } \\
\text { past year }\end{array}$ & $2.3(1.30$ to 4.15$)$ & 0.005 & & \\
\hline $\begin{array}{l}\text { Belief vaccine is }<75 \% \\
\text { effective }\end{array}$ & $0.6(0.39$ to 0.95$)$ & 0.03 & 0.5 (0.39 to 0.71$)$ & $<0.001$ \\
\hline $\begin{array}{l}\text { Peers strongly } \\
\text { approve of vaccine }\end{array}$ & $2.1(1.42$ to 3.20$)$ & $<0.001$ & $1.5(1.15$ to 1.91$)$ & 0.002 \\
\hline Currently attending school & - & - & $1.3(1.03$ to 1.70$)$ & 0.03 \\
\hline$>5$ sex partners & - & - & $1.3(1.02$ to 1.71$)$ & 0.04 \\
\hline $\begin{array}{l}\text { Low perceived } \\
\text { susceptibility to HPV }\end{array}$ & - & - & $0.6(0.43$ to 0.80$)$ & 0.001 \\
\hline
\end{tabular}

${ }^{*} \mathrm{APR}(95 \% \mathrm{Cl})=$ adjusted prevalence ratio and $95 \% \mathrm{Cl}$ from Poisson regression with robust standard errors; adjusted for all characteristics listed in table. Further adjustment for the following characteristics made no appreciable difference in the estimates and were not included: race, education (self or parent), marital status, income, sexually active in the past 3 months, lifetime number of sex partners, condom use, history of HPV-related conditions, history of STD, religious preferences, physical health, mental health, binge drinking, and severity of or susceptibility to HPV infection.

†Excluding marijuana use.

\section{P5-S6.31 SEXUAL HEALTHCARE AMONG FEMALE SEX WORKERS WORKING OUTSIDE OF THE MAIN ENTERTAINMENT DISTRICT IN TIJUANA, MEXICO}

doi:10.1136/sextrans-2011-050108.587

${ }^{1} \mathrm{M}$ Rusch, ${ }^{2} \mathrm{M}$ Gallardo, ${ }^{2} \mathrm{R}$ Lozada, ${ }^{3} \mathrm{R}$ Lindsay, ${ }^{1} \mathrm{~V} \mathrm{~J}$ Mercer, ${ }^{1} \mathrm{M}$ L Zuniga, ${ }^{1} \mathrm{~T}$ L Patterson, ${ }^{1} \mathrm{~S}$ A Strathdee. ${ }^{1}$ UCSD, La Jolla, USA; ${ }^{2}$ PrevenCasa A.C., Mexico; ${ }^{3}$ SDSU-UCSD, USA

Background Sex work is quasi-legal in Tijuana, with a zone of tolerance (Zona Roja, or Red Light district), and a registration card system whereby female sex workers (FSW) pay an annual cost to cover HIV and STI testing. As healthcare efforts are concentrated in the Zona Roja, we set out to assess the frequency of Pap testing among FSW working outside this zone.

Methods Proyecto Amantes de la Salud (Lovers of Health Project) conducted baseline surveys among 403 FSW working in bars outside of Tijuana's Zona Roja using time-location sampling. Surveys included demographics, sexual and substance use behaviour, sex work characteristics and sexual healthcare practices. Average number of annual Pap tests over the past 5 years was calculated using left censoring for the denominator based on: (1) years sexually active and (2) years in sex trade. Descriptive statistics and logistic regression were used to assess factors associated with Pap testing in the past year

Results Participants ranged in age from 18 to 55 (Median: 28; IOR: 23-32); all were born in Mexico and 98\% reported being registered as an FSW. Sex partners included regular, non-client $(25 \%)$, regular clients (79\%) and non-regular clients (99\%). Overall, 85\% of women reported a pap test in the past year; however, only $35 \%$ of sexually active women and $52 \%$ of FSW had an average of at least one Pap test per year over the past 5 years see Abstract P5-S6.31 table 1. A

Abstract P5-S6.31 Table 1 Factors associated with reporting a Pap test in the past year among FSW in Tijuana, Mexico

\begin{tabular}{|c|c|c|c|}
\hline & $\begin{array}{l}\text { Pap test } \\
\text { past year, } \\
\mathrm{N}=344(85 \%)\end{array}$ & $\begin{array}{l}\text { No Pap } \\
\text { past year, } \\
N=59(15 \%)\end{array}$ & $\begin{array}{l}\text { AOR } \\
(95 \% \mathrm{Cl})\end{array}$ \\
\hline Age $<25$ & $99(29 \%)$ & $25(42 \%)$ & $0.44(0.18$ to 1.10$)$ \\
\hline \multicolumn{4}{|l|}{ Work colonia } \\
\hline Region A & $162(47 \%)$ & $22(37 \%)$ & - \\
\hline Region $B$ & $182(53 \%)$ & $37(63 \%)$ & - \\
\hline Lived in TJ whole life & $107(31 \%)$ & $20(34 \%)$ & - \\
\hline \multicolumn{4}{|l|}{ Education } \\
\hline$\geq 6 \mathrm{yrs}$ & $178(52 \%)$ & $28(48 \%)$ & - \\
\hline Any child & $235(68 \%)$ & $30(51 \%)$ & $2.08(0.94$ to 4.58$)$ \\
\hline Income $>3500 \mathrm{pesos} / \mathrm{mos}$ & $231(67 \%)$ & $54(92 \%)$ & $0.32(0.11$ to 0.97$)$ \\
\hline Years of SW & $6(3,9)$ & $6(3,10)$ & $0.89(0.83$ to 0.97$)$ \\
\hline Regular partner & $87(25 \%)$ & $13(22 \%)$ & - \\
\hline Casual partner (any) & $134(39 \%)$ & $19(32 \%)$ & - \\
\hline Regular clients (any) & $263(76 \%)$ & $55(93 \%)$ & $0.29(0.10$ to 0.84$)$ \\
\hline $10+$ non-regular clients & $239(69 \%)$ & $47(80 \%)$ & - \\
\hline $\begin{array}{l}\text { Condom use }<1 / 2 \text { time* } \\
\text { (regular clients) }\end{array}$ & $92(35 \%)$ & $9(16 \%)$ & - \\
\hline $\begin{array}{l}\text { Condom use }<1 / 2 \text { time } \\
\text { (non-regular clients) }\end{array}$ & $77(22 \%)$ & $3(5 \%)$ & 3.56 (0.90 to 14.09$)$ \\
\hline US clients & $133(39 \%)$ & $17(29 \%)$ & - \\
\hline Alcohol daily & $117(34 \%)$ & $11(19 \%)$ & - \\
\hline Any drug use & $42(12 \%)$ & $7(12 \%)$ & - \\
\hline Drug use $\mathrm{w} /$ clients & $35(10 \%)$ & $5(8 \%)$ & - \\
\hline STI past (6 mos) & $8(2.3)$ & $0(0 \%)$ & - \\
\hline Symptoms past (6 mos) & $45(13 \%)$ & $9(15 \%)$ & - \\
\hline $\begin{array}{l}\text { Used Antibiotics for } \\
\text { STI w/out prescription (ever) }\end{array}$ & $43(13 \%)$ & $3(5 \%)$ & - \\
\hline
\end{tabular}

